\title{
Metabolic fate of glutamine in lymphocytes, macrophages and neutrophils
}

R. Curi ${ }^{1}$, P. Newsholme ${ }^{2}$, T.C. Pithon-Curi ${ }^{1}$, M. Pires-de-M elo ${ }^{3}$, C. Garcia ${ }^{1}$

P.I. Homem-de-Bittencourt Jr. ${ }^{4}$ and A.R.P. Guimarães ${ }^{5}$

\author{
1Departamento de Fisiologia e Biofísica, Instituto de Ciências Biomédicas, \\ Universidade de São Paulo, São Paulo, SP, Brasil \\ ${ }^{2}$ Department of Biochemistry, U niversity College of D ublin, Ireland \\ ${ }^{3}$ Departamento de Ciências Biológicas, U niversidade Camilo Castelo Branco, \\ São Paulo, SP, Brasil \\ ${ }^{4}$ Departamento de Fisiologia e Biofísica, Instituto de Biociências, \\ Universidade Federal do Rio Grande do Sul, Porto Alegre, RS, Brasil \\ ${ }^{5}$ Departamento de Nutrição, Universidade Estadual do Ceará, Fortaleza, CE, Brasil
}

\section{Correspondence \\ R. Curi \\ Departamento de Fisiologia \\ e Biofísica, ICB, USP \\ Av. Prof. Lineu Prestes, 1524 \\ 05508-900 São Paulo, SP \\ Brasil \\ Fax: + 55-11-818-7285 \\ E-mail: ruicuri@fisio.icb1.usp.br \\ Research supported by FAPESP, \\ CNPq, CAPES, PRONEX (No. 168/97) \\ and the British Council. \\ Dr. Philip Newsholme was a \\ visiting professor supported \\ by FAPESP (No. 1997/9725-3). \\ This review is dedicated to \\ Prof. E.A. Newsholme, \\ Department of Biochemistry, \\ O xford U niversity, to celebrate his \\ retirement in September 1996.}

Received April 17, 1998

Accepted O ctober 21, 1998

\section{Abstract}

Eric Newsholme's laboratory was the first to show glutamine utilization by lymphocytes and macrophages. Recently, we have found that neutrophils also utilize glutamine. This amino acid has been shown to play a role in lymphocyte proliferation, cytokine production by lymphocytes and macrophages and phagocytosis and superoxide production by macrophages and neutrophils. Knowledge of the metabolic fate of glutamine in these cells is important for the understanding of the role and function of this amino acid in the maintenance of the proliferative, phagocytic and secretory capacities of these cells. Glutamine and glucose are poorly oxidized by these cells and might produce important precursors for DNA, RNA, protein and lipid synthesis. The high rate of glutamine utilization and its importance in such cells have raised the question as to the source of this glutamine, which, according to current evidence, appears to be muscle.

\section{Introduction}

Lymphocytes, macrophages and neutrophils play an important role in the immune and inflammatory response. Mature lymphocytes recirculate via blood and lymph through lymphoid tissues in a relatively quiescent state until stimulated to proliferate during, for example, a bacterial or viral infection. In contrast, macrophages are terminally differentiated end-cells whose ability to proliferate is gradually lost. Neutrophils constitute $60 \%$ of the circulating leukocytes. They act as first-line-of-defense cells in plasma and perform phagocytosis either alone or in cooperation with antigen-specific defenses.

In recent years, the molecular biology of these cells and the process of chemical com- munication between them have attracted considerable interest and much progress has been made in the understanding of some aspects of the immune system. This system is of fundamental importance not only in preventing or limiting infection, but also in the overall process of repair and recovery from injury. It is therefore important in clinical conditions of trauma, sepsis, burns and recovery from surgery $(1,2)$. The significance of the cellular immune system in overcoming infection has been recently highlighted by the high mortality rate associated with simple immune challenges in acquired immune deficiency syndrome. But the immune system may also play a role in the prevention of cancer by being able to detect abnormal cells. This is the hypothesis of immunosurveil- 
lance. Furthermore, selective heightened activity of the immune system may explain a number of pathological conditions (e.g., diabetes mellitus type I, multiple sclerosis, osteoarthritis, rheumatoid arthritis, and ulcerative colitis) - usually defined by the general term autoimmunity.

Despite the undoubted importance of the cells of the immune system, it is surprising that, until recently, relatively little was known about their metabolism, the fuels they require to carry out their functions, the rates of utilization and fates of the fuels used and any implications for the overall metabolic homeostasis of the animal.

Indeed, it was not until the pioneering

Table 1 - Maximum activities of glucose-, fatty acids, ketone bodies and glutaminemetabolizing enzymes in rat macrophages, lymphocytes and neutrophils.

Lymphocytes and macrophages were prepared and extracted and enzymes were assayed as described by Newsholme et al. (4) and neutrophils as described by PithonCuri et al. (6). Activities were measured at $25^{\circ} \mathrm{C}$, except for glutaminase and phosphoenolpyruvate carboxykinase $\left(37^{\circ} \mathrm{C}\right)$. The results are from Newsholme et al. (4), Curi et al. (7) and Pithon-Curi et al. (6).

\begin{tabular}{|c|c|c|c|}
\hline \multirow[t]{2}{*}{ Enzymes } & \multicolumn{3}{|c|}{$\mathrm{nmol}$ min $^{-1}$ mg protein-1 } \\
\hline & Lymphocytes & Macrophages & Neutrophils \\
\hline Hexokinase & 17.3 & 76 & 33 \\
\hline Phosphorylase & 3.8 & 3.0 & - \\
\hline 6-Phosphofructokinase & 25.7 & 22.8 & - \\
\hline Pyruvate kinase & 403.0 & 447.0 & - \\
\hline Lactate dehydrogenase & 823.0 & 764.0 & 880.0 \\
\hline Glucose 6-phosphate dehydrogenase & 17.5 & 34.5 & 68.0 \\
\hline 6-Phosphogluconate dehydrogenase & 21.1 & 23.8 & - \\
\hline Pyruvate dehydrogenase & 3.3 & 3.2 & - \\
\hline Citrate synthase & 63.7 & 108.0 & 45.0 \\
\hline $\mathrm{NAD}^{+}$-linked isocitrate dehydrogenase & 6.3 & 5.8 & 19.0 \\
\hline NADP-linked isocitrate dehydrogenase & 26.9 & 27.4 & 65.0 \\
\hline ATP citrate lyase & 1.1 & 1.6 & - \\
\hline Oxoglutarate dehydrogenase & 5.1 & 10.1 & - \\
\hline 3-Oxoacid CoA-transferase & 19.9 & 36.6 & - \\
\hline Acetoacetyl-CoA thiolase & 27.4 & 15.5 & - \\
\hline 3-Hydroxybutyrate dehydrogenase & 4.8 & 0.17 & - \\
\hline Carnitine palmitoyltransferase & 0.47 & 0.75 & - \\
\hline Phosphate-dependent glutaminase & 39.4 & 152 & 56 \\
\hline Glutamate dehydrogenase & 34.0 & 98.6 & - \\
\hline NADP-linked malate dehydrogenase & 3.5 & 0.001 & 4.5 \\
\hline Phosphoenolpyruvate carboxykinase & 4.9 & 7.6 & - \\
\hline Pyruvate carboxylase & 2.5 & 4.7 & - \\
\hline Aspartate aminotransferase & 67.4 & 118 & 51 \\
\hline Alanine aminotransferase & 10.3 & 4.4 & 26 \\
\hline $\mathrm{NAD}^{+}$-linked malate dehydrogenase & - & - & - \\
\hline
\end{tabular}

work of Eric Newsholme's laboratory in the 1980's that it was established that immune cells such as lymphocytes and macrophages could utilize glutamine at high rates in addition to glucose $(3,4)$. It was generally thought at that time that glutamine was only a quantitatively important fuel for cells of the intestine and liver, and tumor cells (5). A recent study from our laboratory has shown that neutrophils also utilize glutamine at high rates (6). The metabolic fate of glutamine in lymphocytes, macrophages and neutrophils will be discussed in the present paper.

\section{Metabolism in isolated cells}

The question arises how is it possible to obtain, initially and relatively quickly, information on the metabolic properties of cells or tissues that are metabolically uncharacterized. One means of obtaining this information is from in vitro catalytic activities of a variety of enzymes. A comparison of activities within the tissue and between different tissues permits the determination of the preliminary characteristics of the metabolism. These can then be tested or investigated by studying flux within the pathways. But which enzymes should be studied? The maximum in vitro catalytic activities of certain key enzymes in different pathways can provide information on the maximal capacities of certain pathways in metabolism. The quantitative value of the approach depends upon the care with which the enzymes are chosen. They must function only in the pathway being assessed and must catalyze non-equilibrium reactions. It should be emphasized that maximum enzyme activities indicate only the maximum potential for the utilization of a particular fuel and cannot determine whether a fuel is actually used in a given situation (5).

The maximal catalytic activities of some key enzymes in the metabolism of rat lymphocytes, macrophages and neutrophils are given in Table 1. These activities indicate 
the possibility that these cells are able to utilize glucose and glutamine. They also suggest that their capacity for the utilization of glucose and glutamine is very high. The rates of utilization of glucose and glutamine and of oxidation of these compounds by the isolated and incubated cells are given in Table 2. Furthermore, on the basis of rates of glucose and glutamine utilization, the rate of end-product formation from these compounds, and glutaminase activity, it appears that, of the glucose and glutamine utilized by these cells, very little is oxidized via acetyl$\mathrm{CoA}$ and the classic citric acid cycle. Glucose is converted almost totally into lactate and glutamine into glutamate, aspartate and lactate (Table 2); for full details of these findings see references $6,7,8$.

\section{Role of glutamine in immune function}

In conditions in which the immune response is impaired such as aging (9) and malnutrition (10) there is a marked change in the activity of phosphate-dependent glutaminase, a key enzyme of glutamine metabolism. Mitogenic stimulation of lymphocytes increases both glutaminase activity and the rate of glutamine utilization (11). In the absence of glutamine, lymphocytes do not proliferate in vitro; proliferation increases greatly with glutamine concentration (12). The presence of Walker 256 tumor in rats promotes an increase in the activity of glutaminase in the lymphoid organs and isolated lymphocytes and macrophages (13). Glutamine utilization has also been shown to be associated with the production of superoxide and interleukin-1 and -6 (14) by macrophages and interleukin-2 by lymphocytes (15). Macrophage-mediated phagocytosis is influenced by glutamine availability (11). Beneficial effects of the provision of glutamine (16) or its precursors (17) have been reported in patients submitted to surgery, radiation treatment or bone marrow transplantation or suffering from injury, sepsis or burns (18).

The mechanism by which glutamine can act to allow high rates of secretory product formation and release must account for the diverse nature of these secretory products. In the formation of the superoxide, NADPH is required by the enzyme responsible for free radical production NADPH oxidase. Glutamine, via catabolic metabolism involving $\mathrm{NADP}^{+}$-dependent malate dehydrogenase (19), can thus generate considerable NADPH for cell requirements. Glucose may also, via metabolism through the pentose phosphate pathway, generate NADPH. However, during periods of active pinocytosis and phagocytosis, glucose and glutamine carbon may

\begin{tabular}{|c|c|c|c|c|c|c|}
\hline $\begin{array}{l}\text { Addition to } \\
\text { incubation medium }\end{array}$ & Glucose & Glutamine & Lactate & Glutamate & Aspartate & $\begin{array}{l}{ }^{14} \mathrm{CO}_{2} \\
\text { production }\end{array}$ \\
\hline \multicolumn{7}{|l|}{ Mouse macrophages } \\
\hline Glucose & -355 & nd & 632 & nd & nd & 11 \\
\hline Glutamine & nd & -186 & 33 & 137 & 25 & 9 \\
\hline \multicolumn{7}{|l|}{ Mouse lymphocytes } \\
\hline Glucose & -42 & nd & 91 & nd & nd & 1.5 \\
\hline Glutamine & - & -223 & 9 & 132 & 59 & 6.1 \\
\hline \multicolumn{7}{|l|}{ Rat neutrophils } \\
\hline Glucose & -460 & & 550 & & & 2.4 \\
\hline Glutamine & & -770 & 320 & 250 & 68 & 6.5 \\
\hline
\end{tabular}


be diverted toward lipid synthesis, by generating pyruvate (as described later in this review) and therefore the pentose-phosphate pathway may be compromised (19). Additionally, glutamine carbon may be used for new amino acid synthesis in periods of active synthesis and secretion of protein molecules such as cytokines $(14,15)$.

\section{Fate of glutamine utilization by lymphocytes, macrophages and neutrophils}

It was generally believed that lymphocytes, macrophages and neutrophils obtain most of their energy by metabolism and oxidation of glucose and that lymphocytes, which had not been subjected to an immune response (resting lymphocytes), were metabolically quiescent. Evidence has recently been obtained that the rate of glutamine utilization by these cells is either similar to or greater than that of glucose, that neither glutamine nor glucose is oxidized fully (almost all of the glucose used is converted to lactate and almost all of the glutamine to glutamate, lactate and aspartate - Table 2). A high rate of glutamine utilization, but only partial oxidation, is characteristic of other cells (e.g. enterocytes, thymocytes, colonocytes, fibroblasts, and tumor cells) (20); that the pathway of glutamine oxidation is partial has been known in tumor cells for some time and the process was termed glutaminolysis by McKeehan (21). On the basis of endproducts of metabolism (Table 2) and maximal activities of some enzymes (Table 1), it is probable that glutamine is utilized by a similar if not identical pathway in macrophages, lymphocytes and neutrophils.

\section{The role of high rates of glutaminoly- sis (and glycolysis) in lymphocytes,} macrophages, and neutrophils

For many years, the question of the advantage of a high rate of glycolysis in tumor cells has been discussed (see reference 22). A similar question can be raised about glutaminolysis. The present work demonstrates that similar metabolic characteristics apply to cells of the immune system despite the fact that the cell biology of these cells is different: the lymphocytes under study are not rapidly dividing, but possess the potential for cell division, the macrophages are terminally differentiated, and the neutrophils have a life span of approximately $10 \mathrm{~h}$. Hence any hypothesis must explain high rates of fuel utilization in cells with widely different characteristics. Furthermore, the quantitative results on lymphocytes and macrophages reported by the authors (see Tables 1 and 2) provide the basis for criticism of previous hypotheses. For example, it has been pointed out that both processes provide metabolic intermediates for biosynthetic pathways (glycolysis provides glucose 6-phosphate for formation of ribose 5-phosphate and for DNA and RNA synthesis, and glycerol 3phosphate for phospholipid synthesis, and glutaminolysis provides ammonia and aspartate for purines and pyrimidines for DNA and RNA synthesis). While this is true, the rates of both glycolysis and glutaminolysis - at least in lymphocytes - are greatly in excess $(>100$ fold) of the requirements for these biosynthetic processes. Another suggestion is that these processes provide energy for the cell: in fact, energy provision is considered to be a major role of glutaminolysis in tumor cells and enterocytes (23). While the capacity for rapid cell division is retained by isolated lymphocytes this does not apply to isolated neutrophils or macrophages which are terminally differentiated cells with little capacity for cell division. However, neutrophils and macrophages have a large phagocytic capacity (requiring a high rate of lipid turnover and synthesis) and secretory activity (19).

\section{Pyruvate metabolism in lymphocytes and macrophages}

Pyruvate is a common product of both 
glycolysis and glutaminolysis and represents a key substrate for full oxidation of glucose and glutamine through the Krebs cycle (7). Since lymphocytes and macrophages utilize glucose and glutamine at high rates but present a low rate of their oxidation, the metabolic fate of pyruvate was then examined.

Lymphocytes and macrophages possess both pyruvate dehydrogenase and pyruvate carboxylase activities. Studies using $\left[1-{ }^{14} \mathrm{C}\right]-$ and $\left[3-{ }^{14} \mathrm{C}\right]$-pyruvate have shown that the rate of incorporation of $\left[1-{ }^{14} \mathrm{C}\right]$-pyruvate into ${ }^{14} \mathrm{CO}_{2}$ by either incubated cells or isolated mitochondria is high, in comparison with the rate of conversion of $\left[3-{ }^{14} \mathrm{C}\right]$-pyruvate to ${ }^{14} \mathrm{CO}_{2}$ which is very low. In cells, the rate of conversion of $\left[3-{ }^{14} \mathrm{C}\right]$-pyruvate to ${ }^{14} \mathrm{CO}_{2}$ is only $6-15 \%$ that of $\left[1-{ }^{14} \mathrm{C}\right]$-pyruvate conversion to ${ }^{14} \mathrm{CO}_{2}$, whereas in isolated mitochondria this ratio is only about $4 \%(22)$. These findings suggest that acetyl-CoA produced via the pyruvate dehydrogenase reaction is not oxidatively decarboxylated by the reactions of the Krebs cycle in lymphocytes and macrophages. Therefore, the fate of acetylCoA derived from pyruvate was then investigated. The maximum catalytic activities of the following enzymes of citrate and acetylCoA metabolism were then measured in lymphocytes: citrate synthase, ATP-citrate lyase, acetyl-CoA hydrolase, acetylcarnitine transferase, HMG-CoA lyase, HMG-CoA synthase, acetoacetyl-CoA thiolase, 3-oxoacidCoA transferase, and 3-hydroxybutyrate dehydrogenase. The quantitative contribution of pyruvate to $\mathrm{CO}_{2}$, lactate, aspartate, alanine, citrate, acetyl-CoA and ketone bodies accounted for the pyruvate metabolized (24). Acetyl-CoA was converted to acetoacetate by reactions which may favor the pathway catalyzed by acetoacetyl-CoA thiolase and 3-oxoacid-CoA transferase. The authors concluded that pyruvate from glucose or glutamine metabolism is directed inter alia at the formation of acetoacetate which may serve as a lipid synthesis precursor. In fact, our previous studies have established that gluta- mine is an important precursor of lipid synthesis in adipocytes (25).

\section{Lipid synthesis from pyruvate in lymphocytes and macrophages}

Only very small amounts of either pyruvate or acetate are incorporated into lipids in 90-min incubated resting mesenteric lymph node lymphocytes (24). The amounts of [3$\left.{ }^{14} \mathrm{C}\right]$-pyruvate and $\left[1-{ }^{14} \mathrm{C}\right]$-acetate incorporated were partitioned, respectively, as follows: 14.8 and $16.3 \%$ for free fatty acids, 4.2 and $8.1 \%$ for triglycerides, 78.4 and $74.7 \%$ for cholesterol, and 2.6 and $0.9 \%$ for cholesterol ester. When pyruvate utilization and metabolism were enhanced by concanavalin A (Con A), then acetoacetate formation was not favored and from this it was proposed that acetyl units may then be directed to lipid synthesis and may also make a contribution to the energy metabolism of activated lymphocytes.

To further investigate the importance of pyruvate as lipid precursor, lymphocytes and macrophages were cultured for $24 \mathrm{~h}$. Under this condition, lymphocytes actively synthesize lipids from $\left[3-{ }^{14} \mathrm{C}\right]$-pyruvate $(26,27)$. Experiments with $\left[1-{ }^{14} \mathrm{C}\right]$-acetate as a lipid precursor showed a close similarity with the rates of incorporation of $\left[3-{ }^{14} \mathrm{C}\right]$-pyruvate into the same lipid fractions. Treatment of lymphocytes with Con A (T cell mitogen) markedly enhanced $\left[1-{ }^{14} \mathrm{C}\right]$-acetate incorporation into a variety of lipids, but the lectin did not affect $\left[3-{ }^{14} \mathrm{C}\right]$-pyruvate incorporation. The results suggest that lymphocytes convert pyruvate into lipids via the acetylCoA pathway and that Con A interferes with lymphocyte lipogenesis but does not seem to affect the pyruvate dehydrogenase reaction. The ability to incorporate pyruvate into certain lipids may have an important role for the rapidly dividing capacity of lymphocytes since the human cancer strain HeLa 155 (a quickly proliferating cell line) also exhibits this feature by converting much more [3- 
$\left.{ }^{14} \mathrm{C}\right]$-pyruvate into lipids than do lymphocytes. In addition, peritoneal macrophages (non-proliferating cells) present a still higher capacity for conversion of pyruvate into lipids. Therefore, the role of pyruvate in lipid synthesis is not restricted to rapidly proliferating cells only. Macrophages present a very high turnover of lipids in the membrane and so lipid synthesis might be required to keep the cell membrane integrity and function.

Several studies have demonstrated that lipids actively regulate immune cell function (25). This effect might occur at least partially due to changes in glucose and glutamine metabolism of these cells (25). These findings support the proposition that glutamine could be a precursor for lipid synthesis in these cells, which in turn might play a role for the function of lymphocyte and macrophage.

\section{Importance of the metabolic fate of glutamine for the immune cell function}

As the rate of utilization of glutamine exceeds that required by biosynthetic purposes, an explanation is required for the observed high rates of utilization. Application of the quantitative theory of metabolic control to branched pathways provides a hypothesis that accounts for the high rate of both glycolysis and glutaminolysis in all cells discussed above, i.e., rapidly dividing cells (e.g. tumor cells), those with the potential for cell division (e.g. lymphocytes, some enterocytes, endothelial cells) and terminally differentiated cells such as macrophages, some enterocytes, colonocytes, and neutrophils.

High rates of glycolysis and glutaminolysis provide precursors for biosynthetic pathways, but the fluxes through these biosynthetic pathways are normally very small in comparison to the fluxes through glycolysis and glutaminolysis. However, the flux through the biosynthetic pathways will increase considerably during the synthesis of DNA, RNA, proteins (such as cytokines) and also lipids (such as phospholipids, cholesterol, and triacylglycerol) for new cell membranes (28). Also the stimulation of the respiratory burst by specific factors demands a substantial increase in the formation of reducing power (NADPH and NADH) for superoxide and hydrogen peroxide production. Since these intermediates play a role in the immune cell function, the provision of glutamine represents an important regulatory factor of their function (29). Therefore, it is important to appreciate that the source of glutamine for use by these cells is the muscle. In fact, glutamine content of skeletal muscle is reduced under intense catabolic conditions such as cancer cachexia (30), a fact that may reflect intense demand for glutamine by cells such as lymphocytes and macrophages. Therefore, muscle amino acid metabolism is indirectly linked to the capacity of immune cells to respond appropriately to a stimulus (31).

\section{Acknowledgments}

This article was written during the visit of Dr. Philip Newsholme to São Paulo from March 11th to April 10th, 1998.

\section{References}

1. Furukawa S, Saito H, Fukatsu K, Hashiguchi $Y$, Inaba T, Lin MT, Inoue T, Han I, Matsuda T \& Muto T (1997). Glutamine-enhanced bacterial killing by neutrophils from postoperative patients. Nutrition, 13: 863-869.
2. Furukawa $S$, Saito $H$, Inaba $T$, Lin $M T$, Inoue T, Naka S, Fukatsu K, Hashiguchi Y, Han I, Matsuda T, Ikeda $S \&$ M Muto $T$ (1997). Glutamine-enriched enteral diet enhances bacterial clearance in protected bacterial peritonitis, regardless of gluta- mine form. J ournal of Parenteral and Enteral Nutrition, 21: 208-214.

3. Ardawi MSM \& Newsholme EA (1983). Glutamine metabolism in lymphocytes of the rat. Biochemical J ournal, 212: 835842. 
4. Newsholme P, Curi R, Gordon S \& Newsholme EA (1986). Metabolism of glucose and glutamine, long-chain fatty acids and ketone bodies by murine macrophages. Biochemical J ournal, 239: 121-125.

5. Newsholme EA, Newsholme P, Curi R \& Ardawi MSM (1988). A role for muscle in the immune system and its importance in surgery, trauma, sepsis and burns. Nutrition, 4: 261-268.

6. Pithon-Curi TC, Pires de Melo M, De Azevedo R, Zorn TMT \& Curi R (1997). Glutamine utilization by rat neutrophils. Presence of phosphate-dependent glutaminase. American J ournal of Physiology, 273: C1124-C1129.

7. Curi R, Newsholme $P \&$ Newsholme EA (1988). Metabolism of pyruvate by isolated rat mesenteric lymphocytes, lymphocyte mitochondria and isolated mouse macrophage. Biochemical J ournal, 250: 383-388.

8. Pithon-Curi TC, Pires de Melo M, Palanch AC, Miyasaka CK \& Curi R (1998). Percentage of phagocytosis, production of $\mathrm{O}_{2}-\mathrm{H}_{2} \mathrm{O}_{2}$ and $\mathrm{NO}$ and antioxidant enzyme activities of rat neutrophils in culture. Cell Biochemistry and Function, 16: 43-49.

9. Serrano MAR \& Curi R (1989). Rates of pyruvate utilization and lactate formation by lymphocytes from young and aged rats. Brazilian J ournal of Medical and Biological Research, 22: 555-559.

10. Dos-Santos MA, Rosa R, Curi R \& Barbieri DHGP (1997). Effect of protein malnutrition on the glycolytic and glutaminolytic enzyme activity of rat thymus and mesenteric lymph nodes. Brazilian J ournal of Medical and Biological Research, 30: 719722.

11. Koyama K, Kaya M, Tsujita J \& Hori S (1998). Effects of decreased plasma glutamine concentrations on peripheral lymphocyte proliferation in rats. European J ournal of Applied Physiology, 77: 25-31.

12. Parry-Billings $M$, Evans J, Calder $P C \&$ Newsholme EA (1990). Does glutamine contribute to immunosuppression after major burns? Lancet, 336: 523-525.

13. Fernandes LC \& Curi R (1997). Reversion of Walker 256 tumor cachexia by insulin treatment. Endocrine-Related Cancer J ournal, 4: 465-474.

14. Yassad A, Lavoinne A, Bion A, Daveau M $\&$ Husson A (1997). Glutamine accelerates interleukin-6 production by rat peritoneal macrophages in culture. FEBS Letters, 413: 81-84.

15. Rohde $T$, Maclean DA \& Pedersen BK (1996). Glutamine, lymphocyte proliferation and cytokine production. Scandinavian J ournal of Immunology, 44: 648-650.

16. Tremel H, Kienle B, Weilemann LS, Stehle P \& Fürst P (1994). Glutamine dipeptidesupplemented parenteral nutrition maintains intestinal function in the critically ill. Gastroenterology, 107: 1595-1601.

17. Le Bricon T, Coudray-Lucas C, Lioret N, Lim SK, Plassart F, Schlegel L, De Bandt J P, Saizy R, Giboudeau J \& Cynober L (1997). Omithine alpha-ketoglutarate metabolism after enteral administration in burn patients: bolus compared with continuous infusion. American J ournal of Clinical Nutrition, 65: 512-518.

18. Ogle CK, Ogle J D, Mao J X, Simon J, Noel J G, Li BG \& Alexander W (1994). Effect of glutamine on phagocytosis and bacterial killing by normal and pediatric burn patient neutrophils. J ournal of Parenteral and Enteral Nutrition, 18: 128-133.

19. Newsholme $P$, Costa Rosa LFBP \& Curi R (1996). The importance of macrophage fuel metabolism to its function. Cell Biochemistry and Function, 14: 1-10.

20. Wilmore DW (1994). Glutamine and the gut. Gastroenterology, 107: 1885-1901.

21. McKeehan WL (1982). Glycolysis, glutaminolysis and cell proliferation. Cell Biology International Reports, 6: 635-647.

22. Hume DA \& Weidemann MJ (1979). Role and regulation of glucose metabolism in proliferating cells. J ournal of the National Cancer Institute, 62: 3-8.

23. Newsholme EA \& Leech AR (1983). Bio- chemistry for the Medical Sciences. Wiley, London, New York.

24. Curi R, Williams JF \& Newsholme EA (1989). Formation of ketone bodies by resting lymphocytes. International J ournal of Biochemistry, 21: 1133-1136.

25. Egami MI, Guimarães ARP, Nascimento Curi CMPO \& Curi R (1993). Effect of fatty acids-rich diets on thymocyte proliferation and thymus involution during growing. Physiology and Behavior, 53: 531-534.

26. Homem de Bittencourt J r PI, Yano MM, Hirata MH, Williams J F \& Curi R (1994). Evidence that prostaglandins modulate lipogenesis in cultured lymphocytes - A comparison with its effect on macrophages and tumor cells. Biochemistry and Molecular Biology International, 33: 463-475.

27. Serrano MA \& Curi R (1992). In vitro effect of glycocorticoids on rates of pyruvate utilization and lactate formation in incubated lymphocytes. Brazilian J ournal of Medical and Biological Research, 25: 313-317.

28. Yassad A, Lavoinne A, Bion A, Daveau M $\&$ Husson A (1997). Glutamine accelerates IL-6 production by rat peritoneal macrophages in culture. FEBS Letters, 413: 81-84.

29. Murphy CJ \& Newsholme P (1998). The importance of glutamine metabolism in murine macrophages and human monocytes to L-arginine biosynthesis and rates of nitrate or urea production. Clinical Science, 95: 397-407.

30. Parry-Billings $M$, Leighton $B$, Dimitriadis GD, Curi R, Bond J Bevan S, Colquhoun A \& Newsholme EA (1991). The effect of tumour bearing on skeletal muscle glutamine metabolism. International J ournal of Biochemistry, 23: 933-937.

31. Rohde $T$, Ullum $H$, Rasmussen JP, Kristensen J H, Newsholme E \& Pedersen BK (1995). Effects of glutamine on the immune system: influence of muscular exercise and HIV infection. J ournal of Applied Physiology, 79: 146-150. 